\title{
African Canadian Students Identify Strategies for Success
}

\author{
Maureen Finlayson \\ Teacher Education, Cape Breton University, Canada
}

\begin{abstract}
In today's educational systems, all students face obstacles and challenges. African Canadian students face unique challenges. This study investigates the perspectives of successful African Canadian students about their educational programs in Nova Scotia, Canada. The purpose of this study is twofold. The first objective is to examine the background and demographic characteristics, and socio-cultural experiences of ten African Canadian students in Nova Scotia. The second objective is to discuss the obstacles, challenges and strategies for success. The voices of these students provide insights into successful strategies for all students. The methodology included contacting ten African Canadian students at diverse levels in public education in Nova Scotia, to interview the participants by asking questions about their background, the obstacles and challenges which they have faced in education, and the strategies which have enabled them to be successful. Interviews are completed, and strategies for success have been analyzed. These data indicate that students have faced many challenges. Furthermore, these data indicate that facing the challenges have empowered the participants to devise strategies which have enabled them to be successful. Critical factors for their success include: family support; role modeling; caring educators; infusing African heritage into the curriculum; having someone believe in them, knowledge and pride in Black cultural and racial identity; and self-motivation. The author suggests that an improved understanding of the lived educational experiences of African Canadian students hold implications for all students and educators.
\end{abstract}

\section{Introduction}

In today's educational systems, all students face many obstacles and challenges. African Canadian educators face unique challenges. This study investigates the challenges and obstacles specific to African Canadian students in Nova Scotia, a small province on the east coast of Canada, and the strategies which they have identified that have helped them to become successful.

This study was carried out by interviewing ten African Canadian students in Nova Scotia.
Specifically, the purpose of this study was twofold. The first objective was to examine the background and demographic characteristics and socio-cultural experiences of African-Canadian students in Nova Scotia. The second objective was to describe the obstacles, challenges which they have faced, and strategies for success. Interviews were conducted and their responses were analyzed to investigate the complex and multifaceted nature of the experiences of these African-Canadian students. The voices of these students provide insights into successful strategies.

\section{Research Rationale}

African Canadian students face unique challenges in education. Primary concerns raised by student responses include: differential treatment by race, the absence of Black teachers, and the absence of African Canadian history and literature in their resources [7]; [7]. Several documents indicate that African Canadian high-school students are marginalized and alienated in Canadian schools [1], [2], and [19]. In research, there have been complaints about racism faced by Black students, the low level of teacher expectations of Black students, the high drop-out rate among Black students, and the overrepresentation of Black students in non-academic programs [8], [16].

This reminds us how important it is to have a research focus on the experiences of African Canadian students in the educational context. A close examination of the challenges and obstacles that Black students face in the classroom indicates that Black students know what these are, and have identified strategies for success. Students have identified that they need teachers with whom they can identify. Scholars in this field have documented that teachers are more effective when they provide cultural connections to the curriculum, draw on student cultures in their teaching styles and address the struggles that their students face [6], [10], [9]. In their research, Carr \& Klassen reminds us that "the attitude of the teacher is crucial in helping students develop attitudes that will prepare them for a harmonious existence in a society that is culturally diverse" [3:69]. Furthermore, Black students when asked what they would like changed, responded that they would like more Black teachers who would understand their situations [7]. I acknowledge the 
importance of this research with its focus on achievement of Black students and how they have become successful.

I want to contribute to this literature of narrative research by examining the life history and educational experiences of ten African Canadian students. It is important to know what challenges they have faced, and what strategies they have created to overcome these challenges and become successful.

\subsection{Research design and goals}

An important feature was the use of the life history method and the choice of participants. The life history method provided a structure to obtain background information, with the flexibility of conversational questions during the interviews. Seidmann [18] has used an interview process to explore the experiences of the participants, their educational experiences and their interactions with members of the communities. This qualitative approach conforms to education research practice and allows the researcher to ask open-ended questions to build upon and explore the participants' responses to these questions.

Interviews were conducted with ten students of African heritage within the educational school system of Nova Scotia. All indicated a willingness to participate in life history interviews. I have selected these individuals as a result of the diversity of their backgrounds and the success which they have had in education. These individuals represented (a) diverse family backgrounds (b) diverse communities; (c) families of varying socioeconomic levels and levels of educational attainment; (d) attendance in predominantly minority or majority schools with teachers from diverse races, cultures and backgrounds.

The goal of this research is to have the participant recount her/his experiences within the topic under study. These questions have guided the data collection and analysis:

(1) Describe your family, community, and academic background, and explain what you think in your background has prepared you to be successful?

(2) What obstacles and challenges have you faced?

(3) What strategies have helped you to be successful?

The data collected has been compiled into themes which link the obstacles and challenges faced by the participants, and their strategies to successfully address these challenges.

\section{Participants}

African Canadian students who participated in this study are successful. A brief description of each participant follows. As you will see, the participants come from a variety of backgrounds, have been raised in Nova Scotia, and have been heavily influenced by the backgrounds and experiences of their parents. Six students are in first and second year of high school; four students have university experience. Two students are in the final year of a Bachelor's degree in university. One has completed a Bachelor of Arts in Criminology; another student has completed her Bachelor of Science, and is upgrading to a honors program, writing a thesis in biology. The Bachelor's programs consist of four years of study after graduation from high school.

The high school students were interviewed as a group of five, and as a single interview. These students attended an urban high school, where students spoke twenty-nine different languages. Yet, these students considered themselves to be a minority in this school. They all spoke of their parents, who had immigrated to Canada, and their struggle to survive. These students acknowledged their parents struggles, and their determination to create a better life for their children. The parents had instilled in them a desire to succeed and the importance of hard work. All of these students were motivated to go to university, determined to have a successful life, and wanted to show their gratitude to their parents, who were working so hard for them. The student, who had been interviewed by herself, spoke proudly of her mother's achievements. This student had returned to Ethiopia to visit extended family. Her desire was to complete her medical training, and then go back to Ethiopia to set up a health care initiative.

The university students had very specific goals. Melissa, who had grown up in a small town, was very involved in her community, in leading activities for youth, and being a role model for them. Melissa had studied science at university, and was determined to go to medical school, and then return to her community to help out the members of her community. Her parents had always encouraged her in her studies.

Micheline and Gabriel are brother and sister. Their parents had immigrated from the Congo. They spoke proudly of what their parents had accomplished and how they had empowered them to become who they are. Gabriel had a degree in criminology and was involved in police work in his community. He had a strong desire to become an RCMP (Royal Canadian Mountie Police) officer. He had worked for the military for short periods of time, and was impressed by the opportunities this provided for him. He had applied to join the RCMP, but had not been accepted as yet. His sister, Micheline, had 
been impressed by her brother's success, and was encouraged and motivated by him to complete her university degree. She wanted to be a teacher and teach French second language programs. Both of them were perfectly bilingual, having completed part of their education in French schools; and part in English schools.

Simus had come from Nigeria to study in Nova Scotia. He had completed his earlier education in Nigeria. He was completing an Engineering degree in petrol. His father had an Engineering degree, and he very much wanted to follow in his father's footsteps. He spoke emotionally about his mother, who had always encouraged him, and believed in him. His goal was to complete his first degree, and then go on to complete his Masters.

\section{Initial Findings}

Based on the data analysis of the life histories, participants identified the following challenges and strategies for success.

\subsection{Isolation and Alienation}

An obstacle identified by all the students was the isolation they often felt. All the students spoke about frequently being the only Black person in a class. Often, they indicated that they each felt very alone and isolated at times. If anything emerged regarding concerns or issues linked to African heritage, people from mainstream society would turn to them individually and expect them to know it all, to have all the answers, and to represent all Black persons.

Sometimes they would raise their hands to offer suggestions and opinions, but were not chosen by teachers to allow them to speak; in fact, they often felt very invisible. One student shared that if questions were asked, he would never be given the challenging question; but rather the question with the easy answer, that everyone would know automatically.

Another student spoke about an assembly, where the principal announced that $95 \%$ of Black students would drop out. When this statement was made, everyone turned to look at her; she was the only Black student in the hall. She was devastated, and felt very alone and isolated.

Two students indicated that they felt isolated from other Black students in the school. There was a large Black population from one community; these two students were not from that community, and were not accepted by the students in the community. These students felt isolated in that they were not part of the White community, nor of the large Black community which existed in that school.

The student from Nigeria indicated how he felt isolated, because he had a different accent. His first language was English; but often, when he spoke, some individuals would say that he had an accent and that they could not understand him. For a period of time, he stopped talking, and went about the university by himself; at one point, he decided he would talk if he wanted to, and overlook these comments. He felt very isolated as a result.

\subsection{Low Expectations by some Educators}

As students, another obstacle was the lack of encouragement by advisors at schools. Many African Canadian students were advised by some guidance counselors and some teachers not to pursue academic courses. When one student inquired about pursuing medicine as a career, he was encouraged to consider physical education studies at university. Other students were advised by their guidance counselor to take high school courses which would not allow them to enter academic programs at university; rather the courses would lead them to graduate or to go to a community college or to a trades program, resulting in a low paying job.

\subsection{Racism}

Racism is an obstacle that all of these African Canadian students spoke about. They indicated that they encountered racism in several ways: negative stereotypes, being called inappropriate names, being invisible, not receiving support from some teachers or being accused by some educators of being lazy, and not wanting to achieve academically. These examples are reinforced by Codjoe [4] who speaks of the persistence of racism and the schooling experience of Black students in Canada. One student spoke about being made fun of by other students because of her hair. Some students and teachers would make comments to them about how natural it was to be good at certain sports; when they had projects to do, often they would be directed to write about basketball or baseball, or some sport as opposed to other students who could choose their own interest.

Racism sometimes occurred at job interviews. Some of the students had applied for jobs, as they were going through school. Often, their applications would be accepted and praised; but when they went for the interview, they would not get the job. After this happened several times, they begin to question the reasons for not being successful, when some of their colleagues who were not African Canadian, would get hired. One student who worked for a clothing store had been there a long time; yet, when a promotion was available, another student employee who worked less time, and was not African Canadian, was promoted to manager.

Students spoke about negative stereotypes which they encountered in the resources. These may be negative stereotypes that indicate that they are only 
good at sports; that they won't succeed academically; that they don't care about getting an education. In some cases, inappropriate words are used in the texts. Sometimes, the teachers simply ignored them and kept on reading or teaching as if the negative stereotypes did not exist, or affect us. All too often, the stereotypes were ignored by the teachers, or dismissed as not being important. African Canadian students, upon hearing and seeing these stereotypes, would sometimes begin to question their self-value and their identity.

\subsection{The Curriculum}

Another concern was raised about the curriculum in schools in Nova Scotia. In the curriculum for all subject areas, there was little mention and more frequently no mention of any contributions of individuals of African heritage. The students mentioned that there was a lack of Black leaders in the resources. In schools or public places of education there were no posters, murals, or environments with Black faces. What does this mean for a Black student? It gives a strong message that Black students are not included, do not belong. When students don't see Black leaders whether in education, in business, in politics, in employment, they don't see these positions as possibilities for them to achieve. Including Black faces in the materials and resources of the curriculum of the public schools on Nova Scotia proved to be a real challenge.

\section{Strategies for Success}

To address these obstacles and challenges, these African Canadian students used a variety of strategies. There were linked to institutional and financial support, family and community support; personal well-being; having a positive attitude and determination to succeed, academic achievement, addressing racism, including African heritage in the curriculum, and the positive impact of educators.

\subsection{Institutional and Financial Support}

An important strategy to address financial needs was through institutional support. The African Canadian Services Division of the Nova Scotia Department of Education provided scholarship funds for students to continue their academic studies at university. Three of the university students received these scholarships while completing their first degree. This relieved some of the pressure of having to raise all the required money to pay for tuition, books, and residence while at university. For all students, having teachers and professors who were supportive of their work and their pursuit of further studies was an essential strategy.

\subsection{Academic Qualifications}

Having strong academic qualifications is an important part of this institutional strategy. When an opportunity arose, if the African Canadian student had the skills and required certificates and qualifications, then she or he could apply. Another strategy mentioned was the importance of keeping up to date on all the latest issues. Being connected through technology enabled students to support one another and to keep informed of what was needed to succeed.

\subsection{Having a Positive Attitude}

A positive attitude and world view was an important strategy. All students spoke of the importance of making small steps, of celebrating these small successes, and of keeping a positive attitude. To be successful, all students spoke of their determination to succeed, and their refusal to give up when challenges seem to be too overwhelming.

One student shared how whenever he felt like giving up, he would think of his mother who would be saying, "Don't ever give up; you have what it takes. Nobody can stop you from doing what you want to do". Another student spoke of how she had gone for a summer job. She was shy, and didn't present her skills and abilities very strongly. The person interviewing her had looked at her resume. He told her how she had a lot to offer, but needed to show this in a positive way. She learned from this interview, she was given the job, and began to use her achievements to build her self-esteem. She shared how this experience had shown her that she could succeed, and she began to believe in herself.

\subsection{Family and Community Support}

A strategy mentioned by all the African Canadian students was the support they received from family members and the extended family. They spoke of the financial and emotional support offered by both parents. From day one in the lives of students their parents have been very supportive, helping them to develop their self-confidence and self-esteem. The parents knew from their own experiences in the Canadian society what their Black children would face in the real world [5]. In one instance, a student spoke, with tears in her eyes, how her parents were always there to help her though the difficult times. She explained that if ever there was an issue of racism, her parents immediately went to the school to see what happened and to have the issue addressed. In another instant, a student shared how she really 
wanted an education, and was the first one in her family to complete high school. Her mother recognized this desire in her, and encouraged her. They didn't have a lot of money, but somehow her mother took on extra tasks, to give her the money she needed for resources, and supplies. She acknowledged how proud her mother was, when she walked across the stage on graduation day.

One student spoke of an uncle, who had been successful, and who encouraged him to complete his education. In one case, the person spoke of her brother who had completed university, in spite of many obstacles; he had become a role model for her, motivating her to return and finish her degree.

Many of the students had community connections and received support from leaders in the community. Whenever many of these students attended events, such as choir practice, musical performances, or Sunday school, these students would be asked how they were doing in school, if they had good results on tests, if they needed help in any way. Many of these community leaders had not been successful in school and wanted to ensure that these young people would have the opportunities that had been denied to them. As a result, the students felt that they had to show the community that they could succeed, and would not let them down. In some cases, when students were having difficulty with math or with language arts, leaders of the community who were knowledgeable, would spend hours tutoring these students and providing the support which they needed.

\subsection{Having a Network of Friends}

An important strategy was that of forming a network of friends. Each student explained that when difficulties arose or when he/she just needed to vent and to talk, having this relationship gave him/her a place he could go to, and talk openly, without having to explain what he/she meant.

At university, Micheline spoke of connecting with students from Africa. She had felt isolated from the Black community at high school. Here at university, she established relationships with students from a variety of countries in Africa. When she was in her third year, she used to search out students in their first year, to connect with them, and make suggestions on how to be successful. She had established numerous friendships, and was in the process of organizing an African Soccer team for women in the area.

Along with this strategy is the importance of being open minded, accepting new ideas, and welcoming new people to become part of your network of friends.

\subsection{Addressing Racism}

Racism was addressed at the institutional level and at the personal level. All African Canadian students agreed that an important way to address racism was through education. Achieving academically was important for Black students to empower them, and to give them the self-confidence and skills to address racism whenever it surfaced. Education was equally important for White students to enable them to understand the pain and suffering that racism causes, and also to become aware of the positive contributions made by of Black members of society.

At the school level, Black student support workers were present to assist students who were struggling with various subjects. They often served as a liaison between the parents and administration, supporting students in whatever way they could.

On a personal level, African Canadian students addressed racism when it arose. Many of the students were involved in sports. They spoke of the importance of building relationships with team members, having them get to know them as friends. This eliminated racism for them many ways. All Black students spoke about the importance of education, of having African heritage as part of all courses, and of providing all students with the opportunity to become aware of the positive contributions of individuals of African descent to community and society.

\subsection{African Heritage in the curriculum}

With regard to the lack of African heritage in the curriculum, the African Canadian Services Division of the Nova Scotia Department of Education responded by insisting that African heritage be incorporated into the curriculum, to be part of the educational year, and not be limited to one month, African Heritage month. African Heritage resources were purchased and placed in schools across Nova Scotia. In his research, Solomon reminds us that "Black educators made sure that curriculum materials reflected a multicultural and antiracist perspective, searched for learning materials with diverse representation, and screened for stereotypes and bias" [20:403].

Two African Heritage courses were available for high school students. English 12: African Heritage language arts [11], African Canadian Studies 11 [11]. Both of these courses provided the history and contributions of individuals of African heritage. Although African Canadian students were not always able to select these courses due to schedule conflicts, many of the students interviewed had completed these courses and had found them very beneficial.

The ACS 11 (African Canadian Studies 11) history course was designed to lay the foundation for 
students to begin to learn about their history and heritage in Canada, in a formal classroom setting. A variety of teaching and learning strategies were used to encourage students to explore in a practical way the following themes: the diversity of African cultures and the development of Canadian identity; the history of the pre-colonial kingdoms of Africa; the transatlantic slave trade; the Middle Passage; the impact of colonial expansion; the African diaspora; forced migration and forced displacement; strategies of resistance and the implications of enslavement on African Canadian settlement; the struggle of peoples of African descent for the pursuit of civil rights and equality; the importance of collective consciousness of peoples of African descent as a strategy for empowerment. As responses to these topics, students used oral and dramatic representations; visual arts, music and dance; portfolios; debate; interviews; field studies and journal writing.

Having completed the ACS 11 course prepared the students well for the E12: African Heritage language arts course. Here they could explore the literature created by writers of African descent. In this course, students completed listening, speaking, reading, viewing, and writing strategies, as well as other ways of representing through fine arts and technology. Topics explored included; Pre-Colonial Africa, Slavery and Resistance, Reconstruction, Renaissance, Social and Political Change, and Contemporary Literature, including Black Women writers. Both of these courses provided excellent opportunities for all students to discuss and share their opinions on issues, which were frequently never discussed in the other history or language arts classes.

For both these courses, students spoke about how teachers had motivated them to learn and how they had obtained a high level of achievement. Teachers who have high expectations for students and motivate learning through culturally relevant teaching have students who learn at high levels [14]. Many studies indicate that teachers' beliefs have a significant impact on students' learning and overall school experience [9].

\subsection{Positive Impact of Educators}

The students in this study spoke of the positive impact that many teachers had on them. They shared how teachers leading the ACS 11 course or the E12: AH language arts course would create opportunities for students to learn about their ancestry and race, and become more positive about being African Canadian. These opportunities could include class discussions with all students involved, or projects, or assignments, or all of these approaches. In their research, McCray et al. emphasized the importance of role models for students to be successful. They stated, "Black children need to see more of our faces every day...Seeing a Black teacher may let some child know that Black people are not just doing something negative [15: 287].

In the introduction to both ACS 11 and E12:AH language arts, teachers created the space for students to talk about negative stereotypes and situations where racism occurs in their lives. Students have the opportunity at this time to say how they feel. Together, students and teachers develop strategies on how to address racism and to make others aware of how these negative experiences are detrimental to all involved. These discussions enabled students to make their voices heard and to become empowered to make positive contributions wherever they live.

Many high school students spoke about teachers who had established relationships with them; getting to know them, their strengths and their weaknesses. In the process, teachers helped students to discover ways in which they could build on their strengths and overcome their weaknesses. Students explained how these teachers would have conversations with them, as they entered the class; they got to know their families and their friends. They used journals on a weekly basis, giving them opportunities to share what they liked or disliked about the course. They gave them choices, when it came to selecting books, or reading materials. The students responded that these teachers respected them, had high expectations for them, and made them work so that they were prepared to go on to further studies, after graduation from high school.

Students always remembered teachers who had believed in them, and who had taken the time to find out about their plans after graduation. They recognized how helpful this had been for them, having someone with whom they could design a plan for the future. They believed that this support, whether through oral conversation, or through helping them establish networks, or by providing references for them, made the difference in their being successful. One student spoke of a viceprincipal, who was of African heritage. This student indicated that he was shy and never volunteered to take any leadership role. This vice-principal came to him one day and asked him to be mc for the upcoming assembly. All 500 students would be present in the gym. At first, he refused; but later when he realized how much she believed in him, he agreed. It turned out to be a great success. He explained how this one gesture had really turned his life around. After this, he felt comfortable to speak in public, and to take on leadership roles. In fact, he went on to organize and lead large celebrations for the Black community in Halifax, every spring.

Most important for these students were the teachers who showed them that they cared about them. In fact, these students remarked that it was only after that a teacher had shown that he/she cared for them, that the student would begin to take notice 
of the knowledge that this teacher had to share with them.

Many students identified teachers who would advocate on their behalf. These students shared that they knew that they could go to a particular teacher in their school, if they had encountered discrimination in any situation. This teacher would listen to them to help them to find ways to address this discrimination. On many occasions, the teacher would advocate on their behalf at staff meetings, or end of term mark reviews, or whenever it was necessary.

Students indicated that they often needed a place to go, to talk to other African Canadian students, or an educator, when they felt overwhelmed. In one case, the students spoke of a vice-principal who had set up a Drop-in Center in the school. This was a place where the students could drop in, talk with others, discuss with other students who were facing the same challenges. The students indicated how they felt that this vice-principal understood that they could go to her whenever they needed someone to talk to. She had a created a space for them.

\section{Conclusion}

For many readers, the perspectives of these ten African Canadian students might be a first glimpse at the obstacles and challenges faced by African Canadian students. It is time to stop and consider the many strategies which they have identified: financial, institutional, and family support; the importance of strong academic qualifications; the inclusion of African heritage in our curricula, the importance of creating strong networks to work together to address the many challenges we face in education; the importance of a positive attitude and a determination to succeed, and the strategies to address racism. They have all identified the positive impact of educators.

All students need to become aware of the challenges and strategies for success of Black students. As educators, we need to be examining the obstacles and challenges identified by these African Canadian students, and to begin to consider their implications for all students. We need to consider how their strategies for success can impact upon all students and we need to learn from these shared experiences. It is important for all students, and in particular for African Canadian students to hear these stories, to know that there are African Canadian students and educators who have paved the way for them.

\section{References}

[1] Alladin, I., (1996) Racism in Canadian schools. Harcourt Brace, Toronto.
[2] Black Learners' Advisory Report. (1994) Halifax, Nova Scotia: Department of Nova Scotia

[3] Carr, P.R., T.R. Klassen. (1997) 'Different perceptions of race in education: racial minority and White teachers', Canadian Journal of Education, 22(1), 67-81.

[4] Codjoe, H.M. (2001) 'Fighting a 'public enemy' of Black academic achievement - the persistence of racism and the schooling experience of Black students in Canada', Race Ethnicity and Education, 4 (4), 343-375.

[5] Codjoe, H. (2007) 'The Importance of Home Environment and Parental Encouragement in Academic Achievements of African Canadian Youths', Canadian Journal of Education 30,(1), 137-156.

[6] Dei, G.J.S. (1993) 'The challenges of anti-racist education in Canada', Canadian Ethic Studies, 25 (2), 3651.

[7] Dei, G. (1996) 'Listening to voices: Developing a Pedagogy of Change from Narratives of African-Canadian Students and Parents', in K. Brathwaite \& C. James (eds.) Educating African Canadians, Toronto, Canada: James Lorimer \& Company Ltd.

[8] Dei, G. (2005) 'Racism in Canadian contexts: Exploring public and private issues in the educational system', In W. J. Tettey, \& K. P. Puplampu, (eds.), The African diaspora in Canada: Negotiating identity and belonging, Calgary, AB: The University of Calgary Press.

[9] Delpit, L. (1995) Other people's children: Cultural conflict in the classroom. New York: New York Press.

[10] Dickar, M. (2008) 'Hearing the silenced dialogue: an examination of the impact of teacher race on their experiences', Race Ethnicity and Education, 11 (2), 115132.

[11] Finlayson, Maureen. (2009) Lead author: Curriculum document African Canadian Studies 11 Curriculum Document. Halifax, Canada: Nova Scotia: Department of Education 1- 82.; Curriculum document (2008) English 12: African Heritage Curriculum Document. Halifax, Canada Nova Scotia: Department of Nova Scotia, 1-81.

[12] Finlayson, Maureen. 2012. 'Exploring unique challenges and successful strategies identified by Black Educators in the Canadian context', Literacy Information and Computer Education Journal (LICEJ), 3, 2, 592-600.

[13] Irvine, J.J. (1990) Black students and school failure: Policies, practices and prescriptions. New York: Greenwood.

[14] Ladson-Billings, G. (1991). Beyond multicultural illiteracy. Journal of Negro Education, 60, 147-157.

[15] McCray, A.D., P.T. Sindelar, K.K. Kilgore., L.L.Neal. (2005). African-American women's decisions to become teachers; sociocultural perspectives. Qualitative Studies in Education, 15(3), 269-290. 
[16] Raby, R. (2004) 'There's no racism at my school, it's just joking around': Ramifications for anti-racist education, Race Ethnicity and Education, 7(4), 367-383).

[17] Sadlier, R. et al. (2009) Black History: Africa, the Caribbean and the Americas. Toronto, Canada: Emond Montgomery Publications.

[18] Seidman, I.E. (1991) Interviewing as qualitative research: A guide for researchers in education and the social sciences. New York: Teachers College Press.

[19] Solomon, P. (1992). Black resistance in high school: Forging a separatist culture. Albany, NY: State University of New York Press.

[20] Solomon, R.P. (1997) 'Race, role modeling, and representation in teacher education and teaching'. Canadian Journal of Education, 22(4), 395-410. 